\title{
Lateral Recessional Moraines in the Green Mountains of Northern Vermont
}

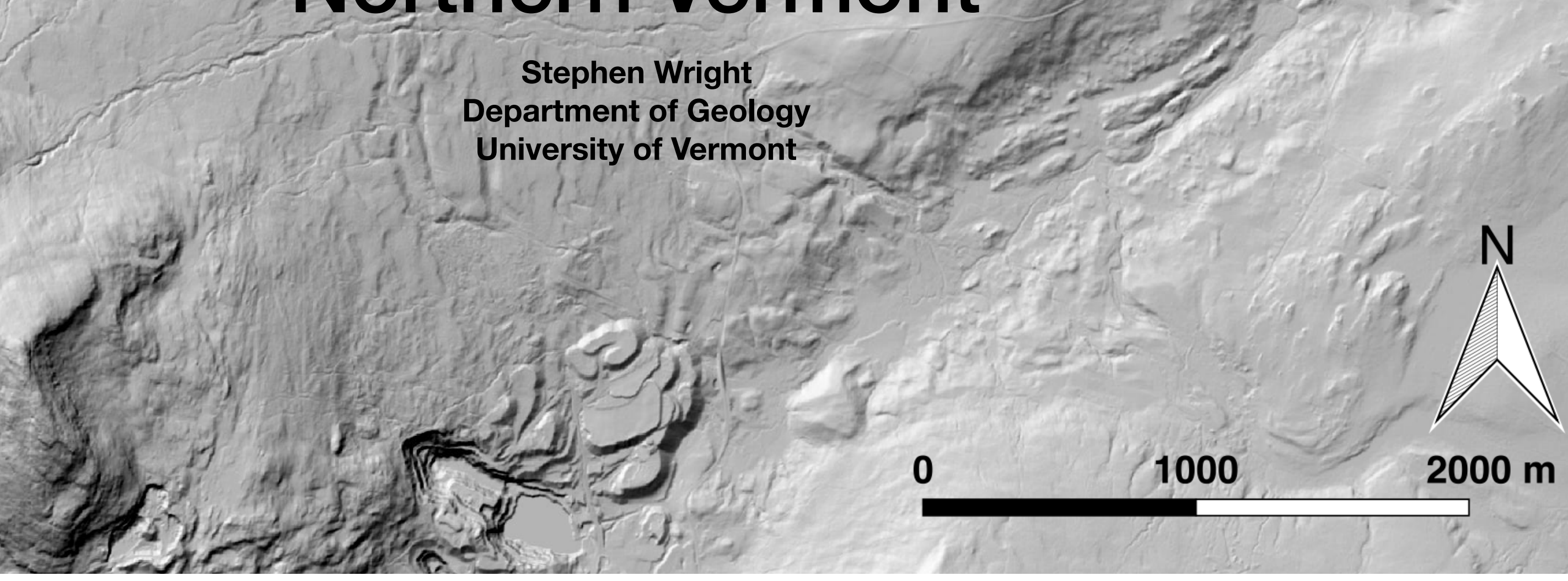




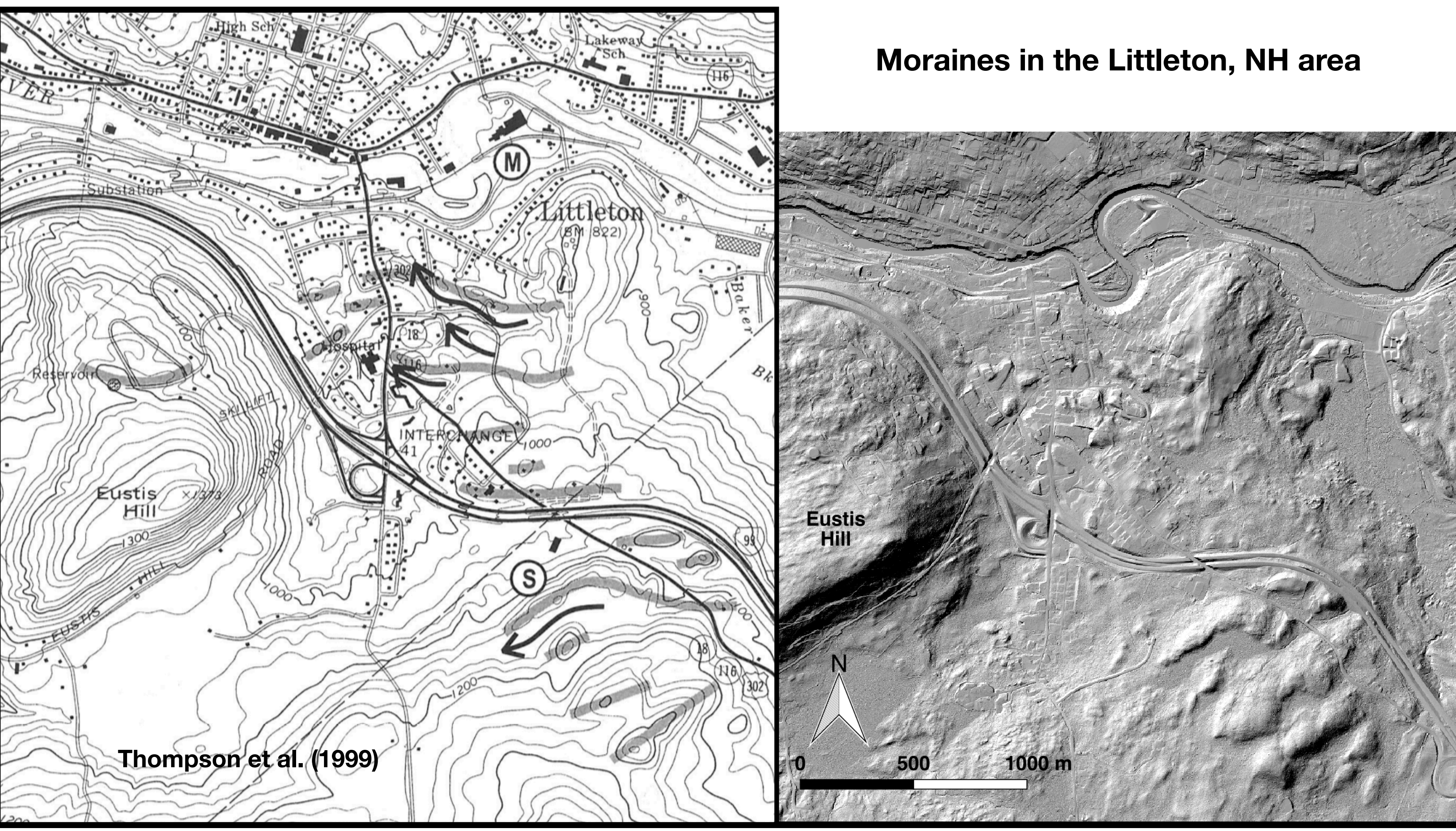




\section{Moraines in the English Lake District}

"A mound, ridge, or other distinct accumulation of .... till, deposited chiefly by direct action of glacial ice... ." AGI Glossy of Geology

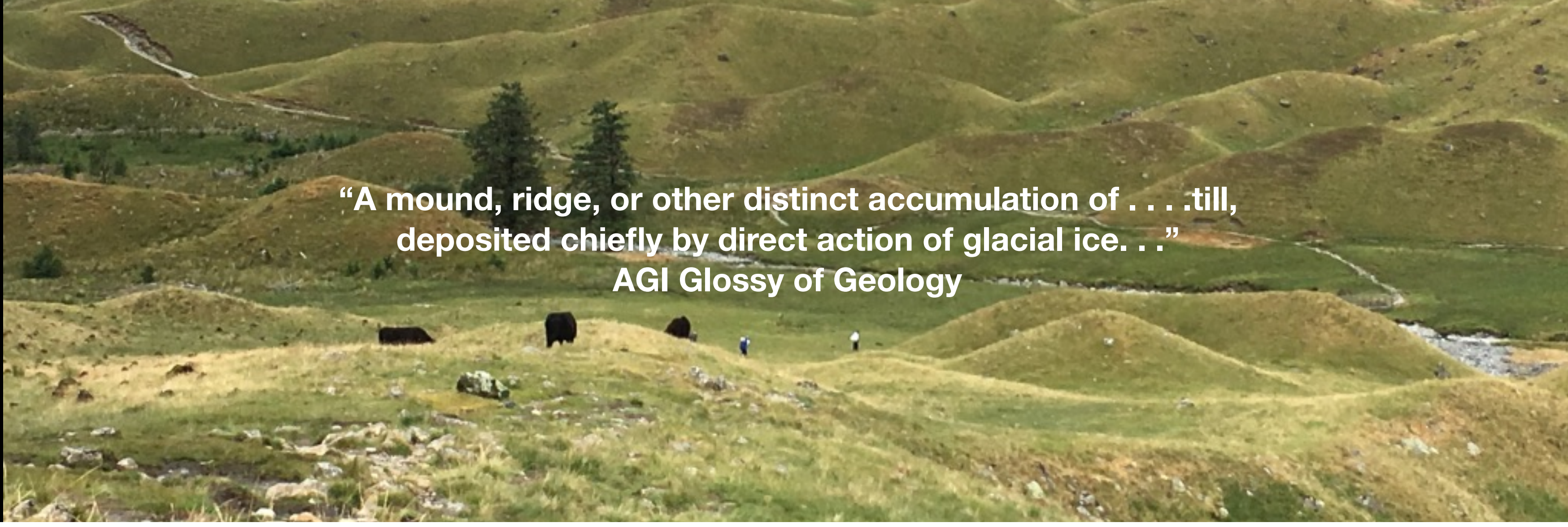




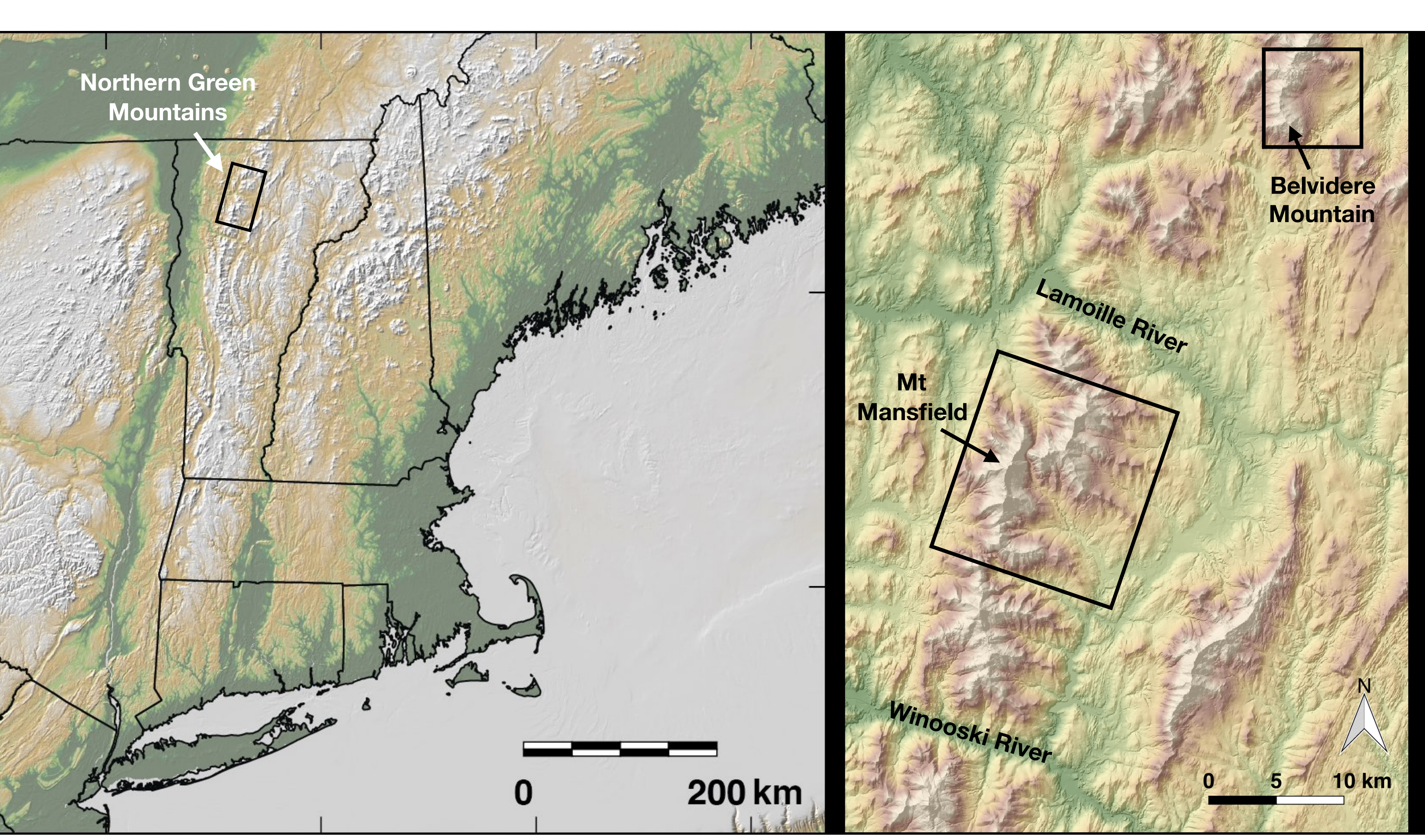




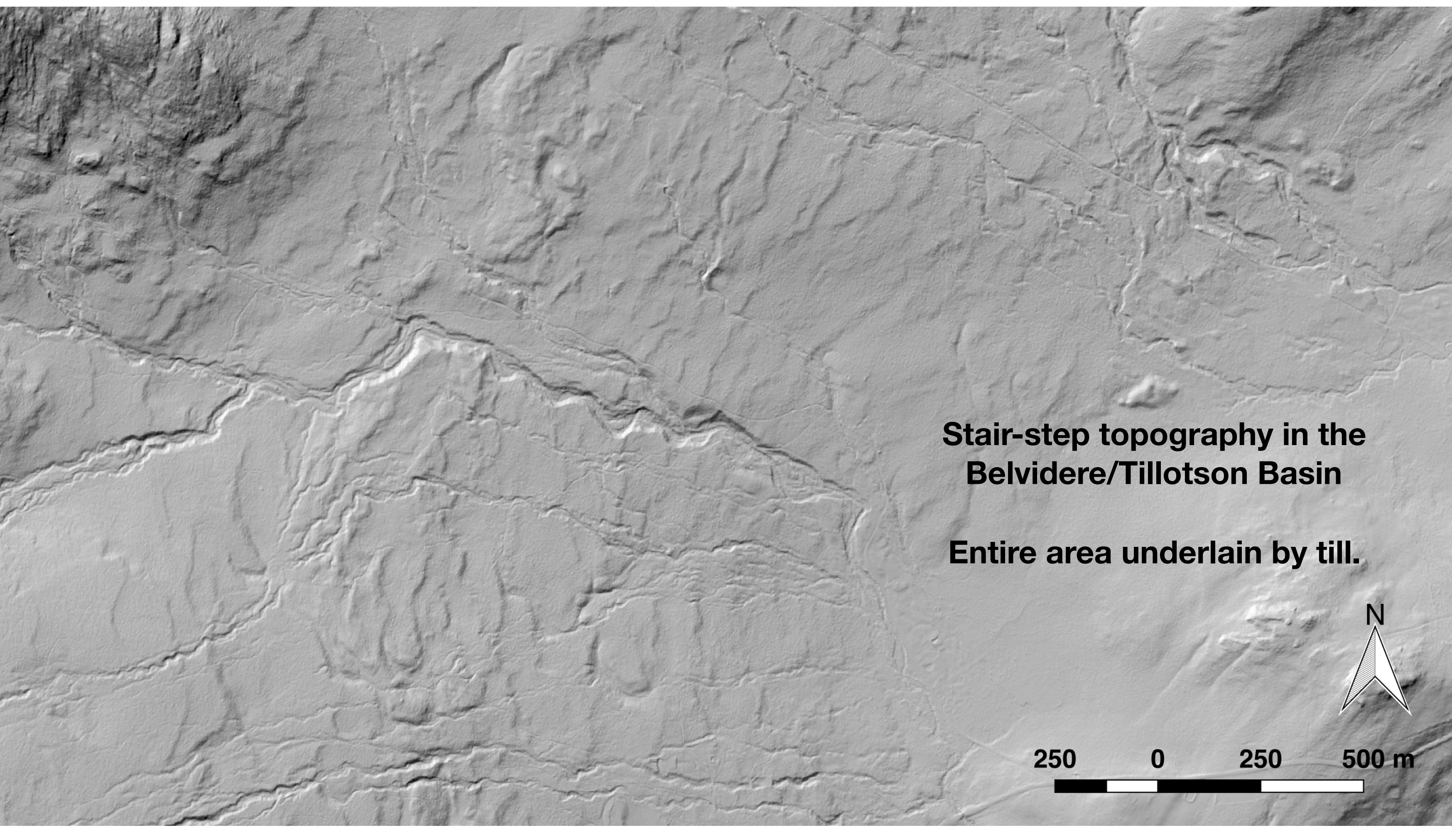




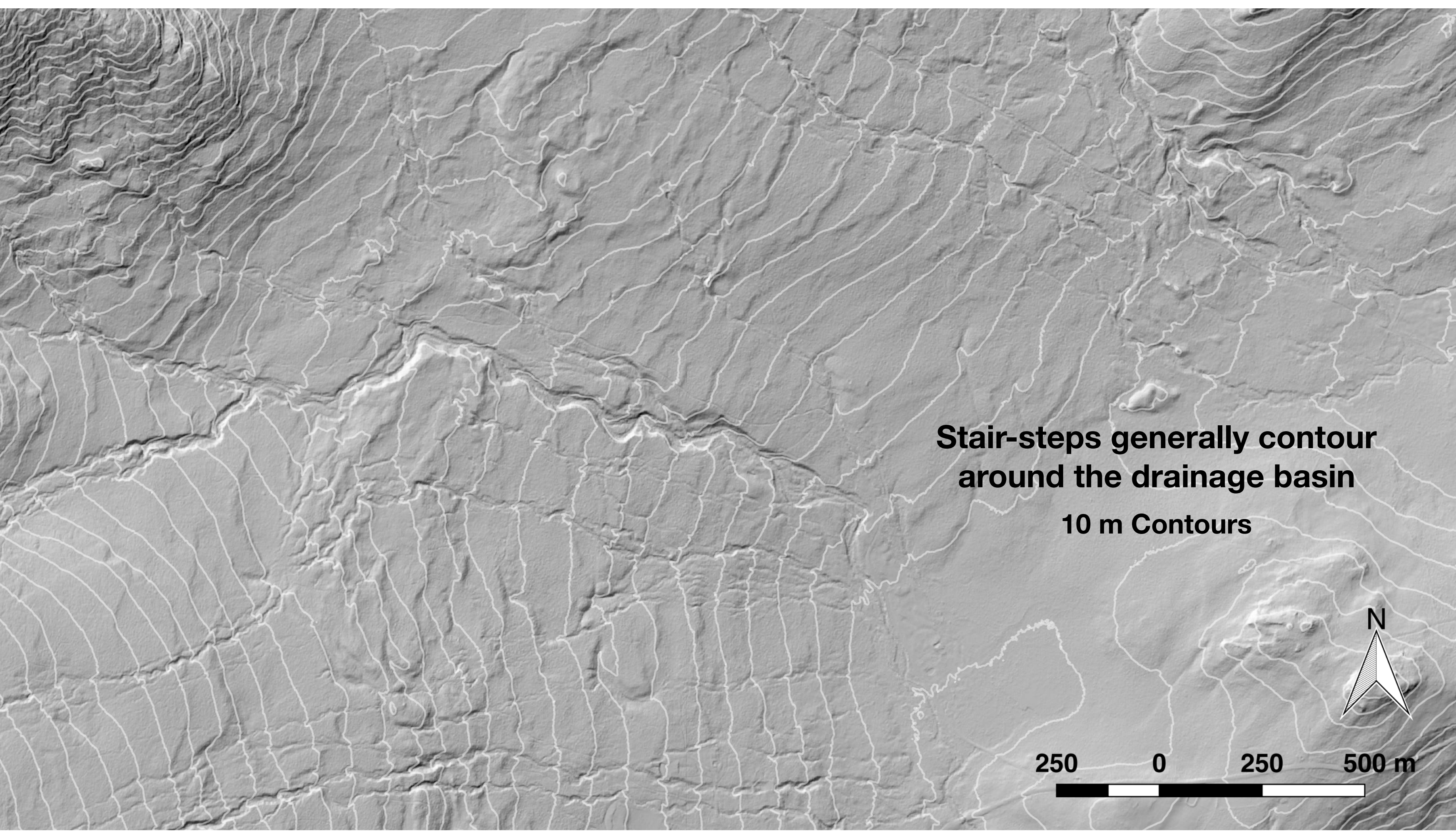




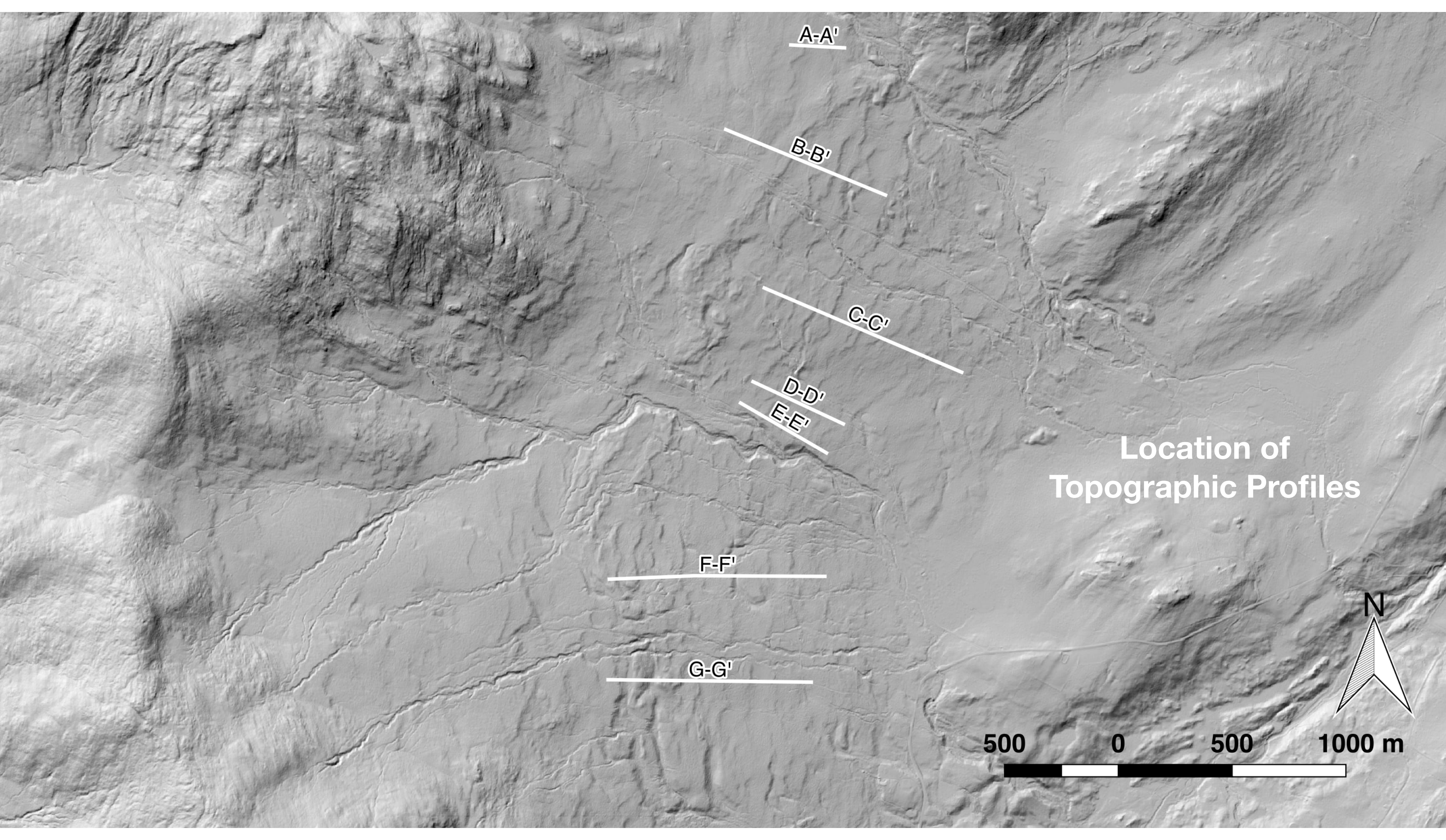




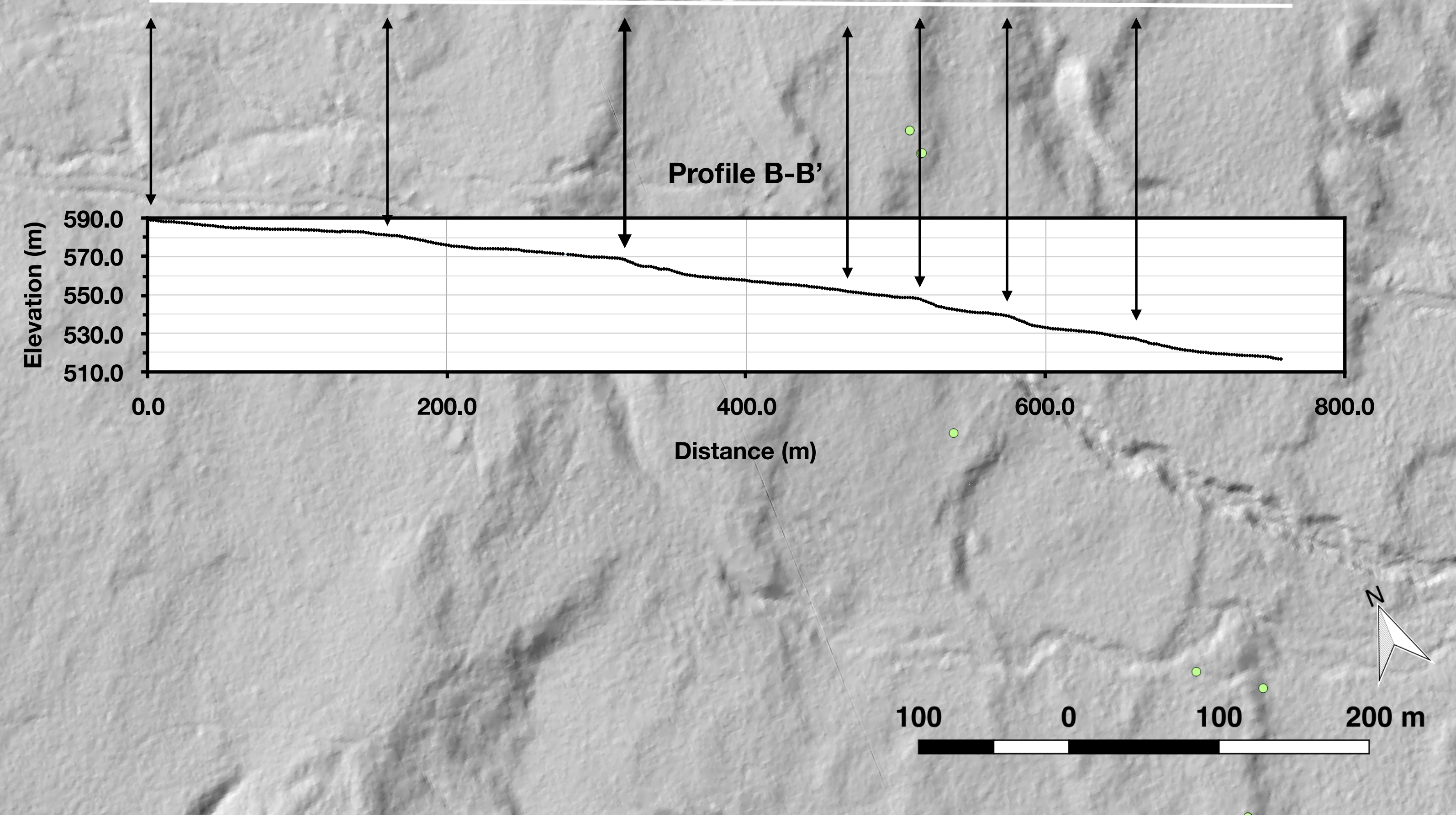




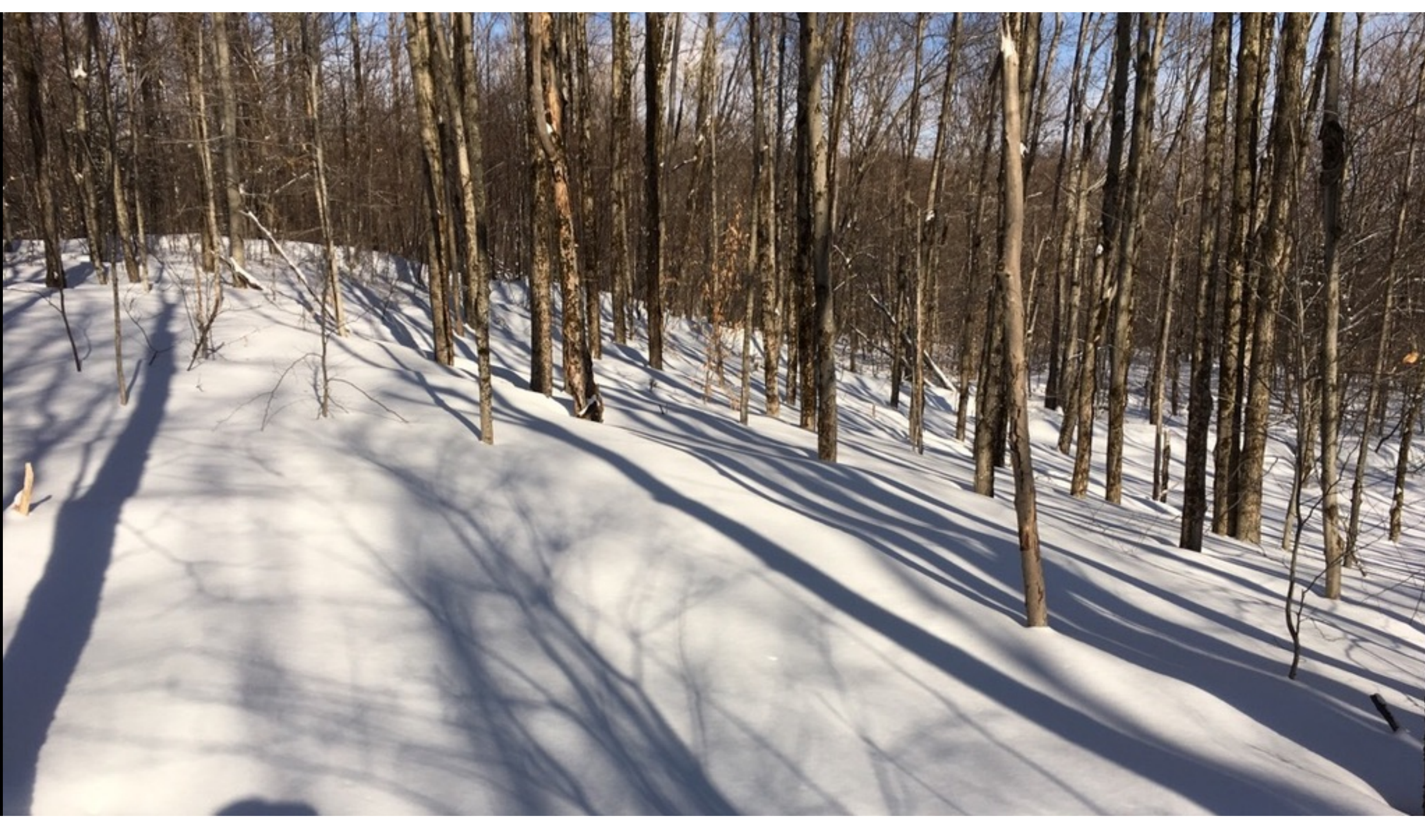




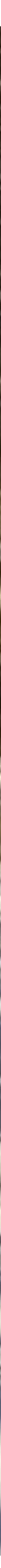


Profile C-C

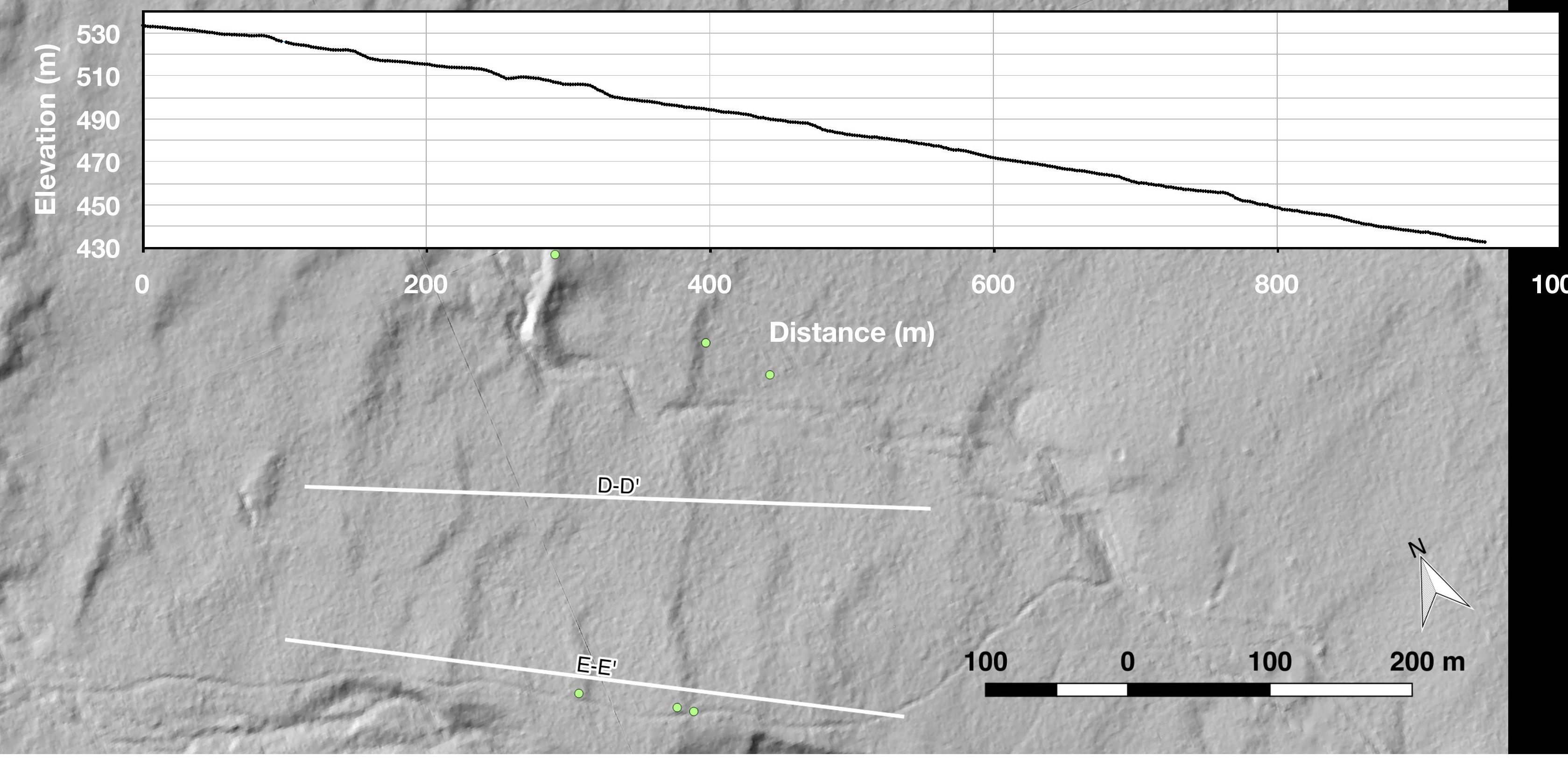




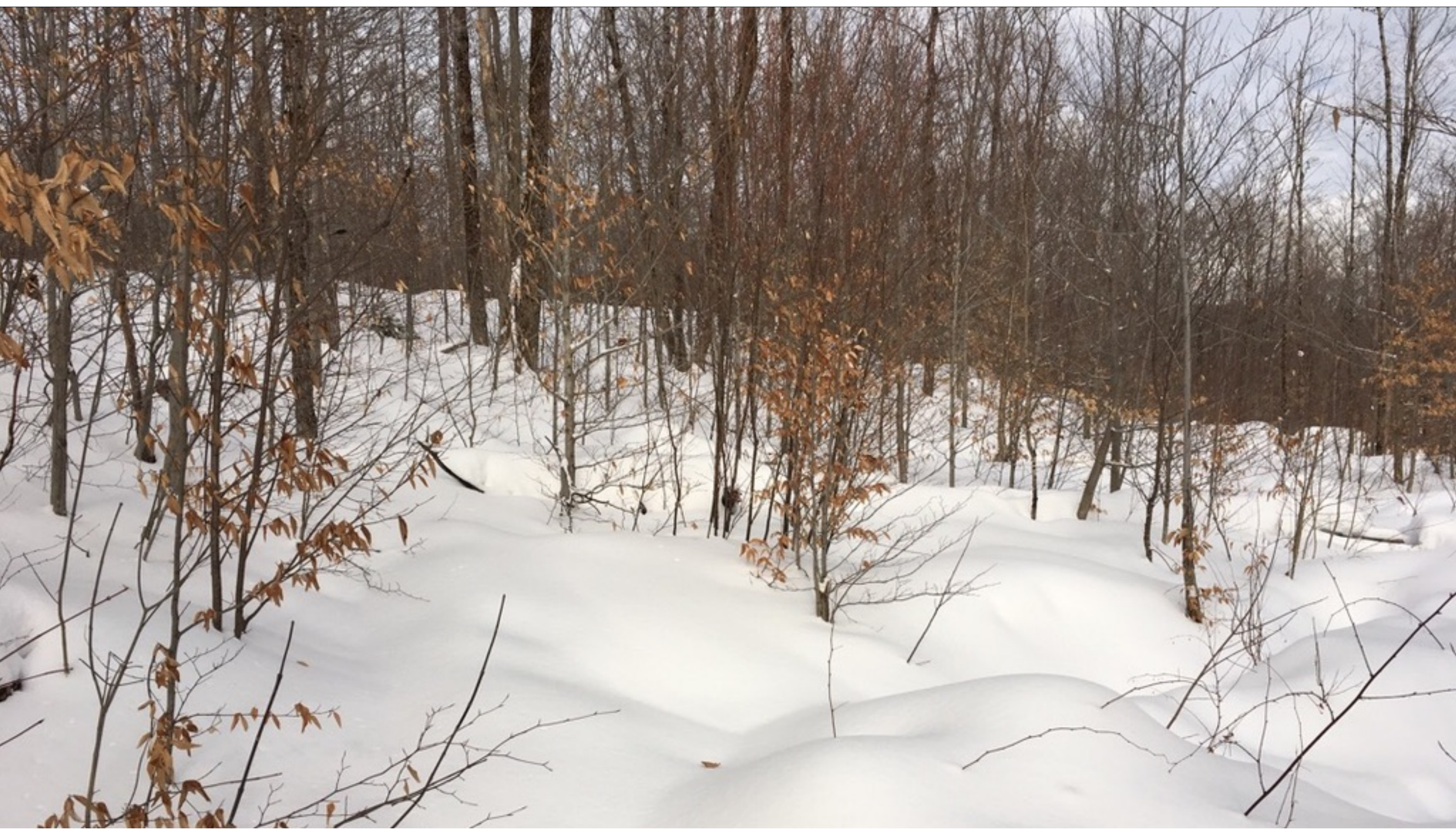




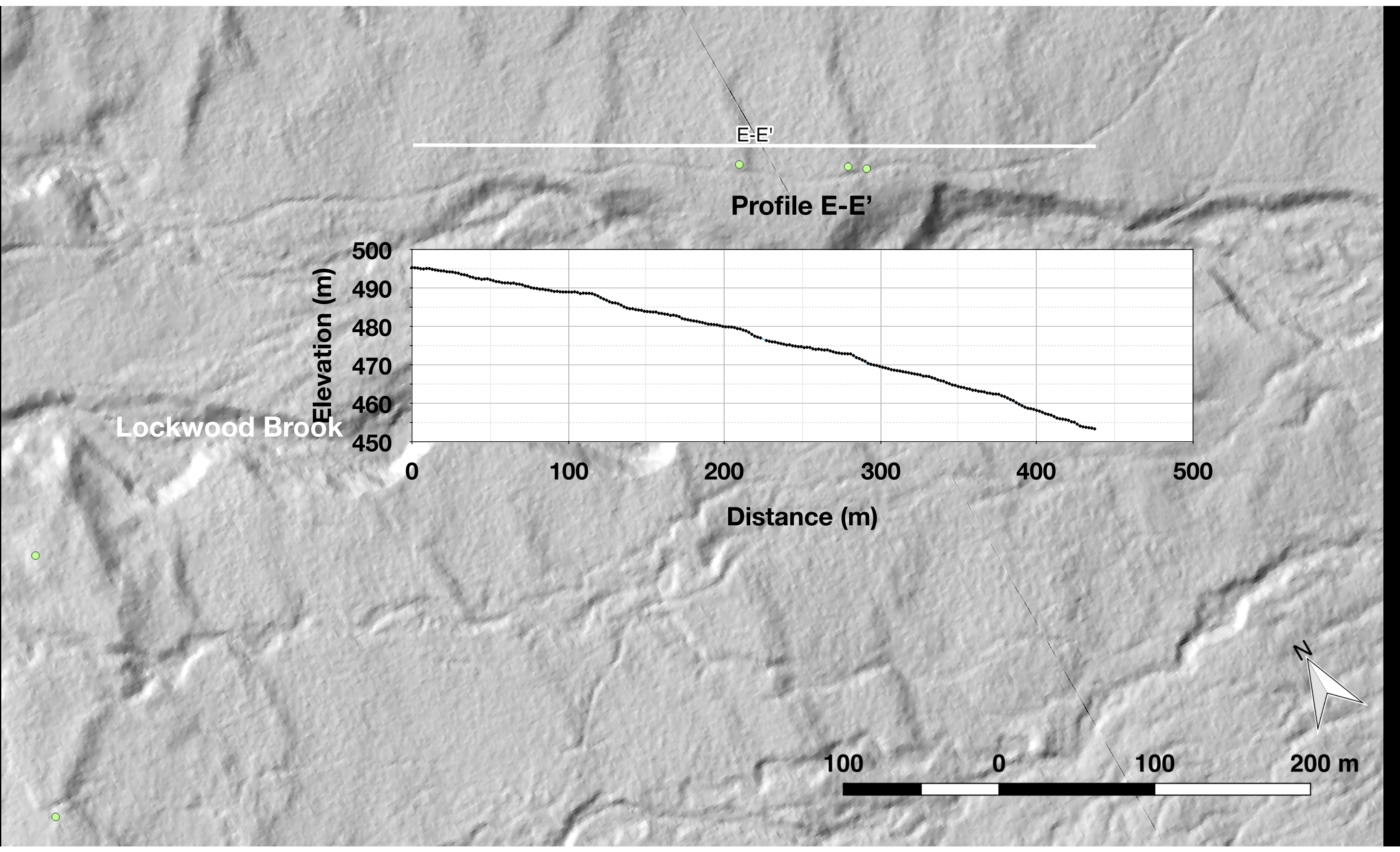




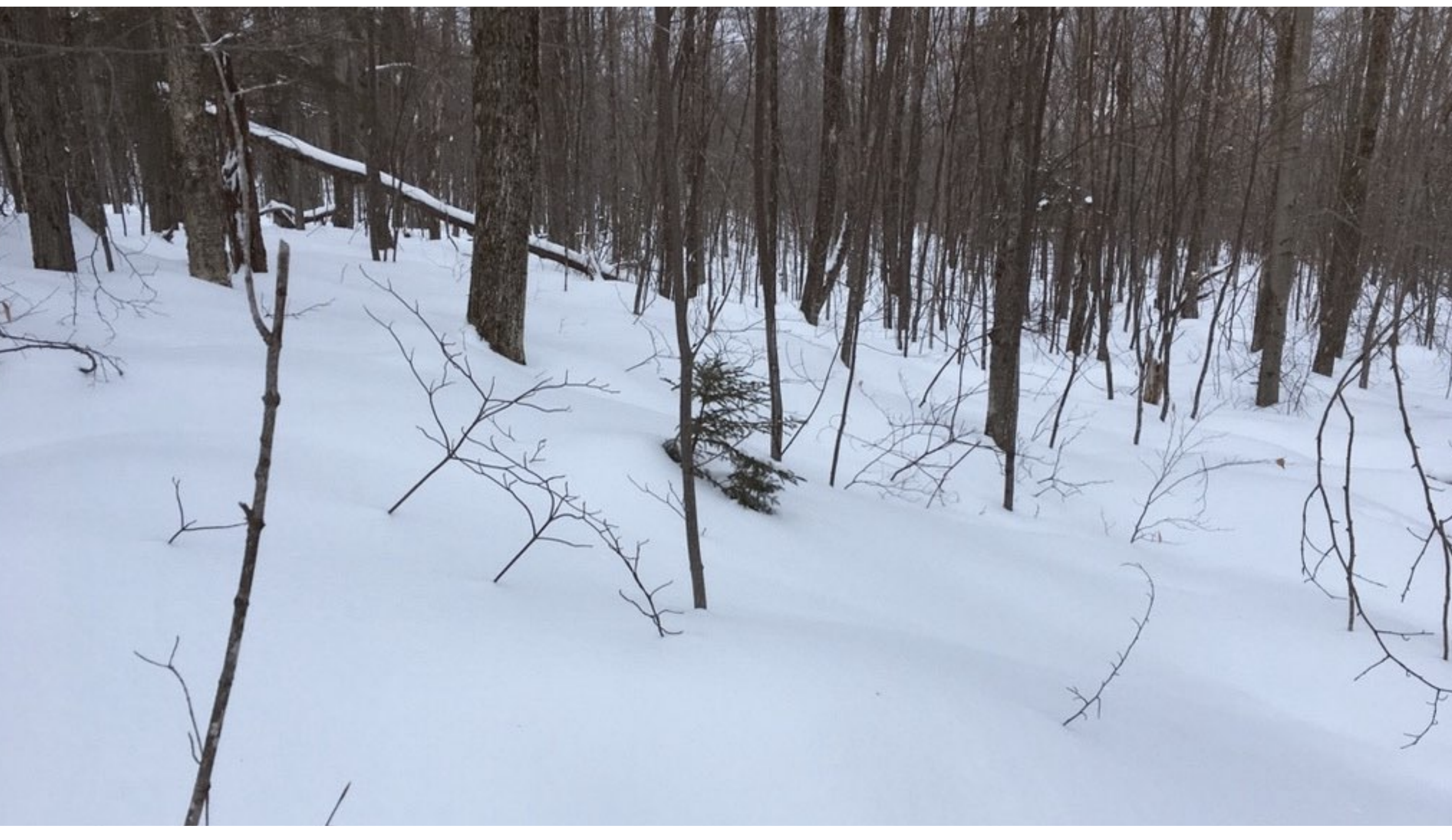

